\title{
Avaliação da dinâmica vocal de um grupo de alunos-atores
}

\author{
Dalva Godoy'
}

\begin{abstract}
Resumo: A presente pesquisa teve como objetivo avaliar o progresso da dinâmica vocal de um grupo de alunos do curso de artes cênicas durante o desenvolvimento da disciplina de expressão vocal. Para tal foi proposto o acompanhamento dos alunos durante três semestres consecutivos através de um protocolo de avaliação que pudesse fornecer subsídios, tanto para o aluno, como para o professor, para o delineamento do trabalho com técnicas vocais que desenvolvessem a expressão adaptada às exigências da voz profissional. Esse protocolo consistiu na avaliação dos tempos de fonação para os fonemas /s/, /z/, /a/, /i/ e / u/ e consequente análise das medidas de tempo máximo de fonação e relação entre os fonemas /s/-/z/. Os resultados mostraram que os alunos se beneficiaram do uso dessas medidas para guiar seu aperfeiçoamento técnico e o professor pôde orientar melhor a proposta pedagógica e até mesmo rastrear encaminhamentos específicos para preservar a saúde vocal dos alunos.
\end{abstract}

\section{Introdução}

Qualquer profissão requer o domínio de habilidades e conhecimentos específicos para se desenvolver de maneira satisfatória e eficaz. Para determinadas profissões, como é o caso, por exemplo, de professores, advogados, locutores, cantores e atores, a voz se configura em um instrumento valioso de trabalho. Para esses profissionais o uso da voz é intenso, seja pela quantidade de horas que se passa falando, seja pelo tipo e qualidade de voz que se exige.

Para Vilkman (2000), dentre as vozes profissionais a que exige mais alto nível de qualidade e demanda é a voz de atores e cantores. A voz dos atores e cantores contrasta com as vozes utilizadas pelos locutores de rádio e televisão, cuja característica principal é a de serem vozes naturais modificadas. Segundo o autor, cantores e atores utilizam vozes artísticas modificadas, cuja qualidade é essencial. As exigências para esse tipo de voz profissional diz respeito tanto às qualidades físicas - altura, intensidade, timbre, etc., como às qualidades psico-sociais. A voz artística deve ser capaz de transmitir não apenas os aspectos presentes na linguagem utilitária do dia-a-dia, ou seja, os pensamentos e sentimentos com precisão, mas também deve ser capaz de dar expressividade àquele que fala e que precisa ser ouvido em um determinado espaço físico.

Berry (2006) enfatiza que a voz do ator precisa conquistar um delicado equilíbrio entre a verdade essencial de sua própria voz e a expressão de sentimentos distintos dos seus que devem ser projetados de forma suficientemente ampla a ponto de atingir todo o espaço que compõe a sala de teatro. Para Stanislavski (1986) a voz do ator deve ser capaz de despertar sentimentos, desejos, pensamentos, imagens e sensações. Para Ferracini (2001) a voz do ator deve ser perfeita estereofonicamente e ter a capacidade de penetrar e envolver o espectador.

Na vida cotidiana a voz transmite os sentimentos e afetos de forma espontânea, mas, no teatro, é preciso construir esse modo de dizer os afetos da personagem. Essa construção se dá, tecnicamente, a partir das va- 
riações de altura, intensidade, articulação e ressonância - aspectos físicos da qualidade vocal. Serão esses aspectos combinados na dinâmica vocal que resultarão em volume, projeção, ritmo, ênfases, pausas, entonações que caracterizam a interpretação teatral. Para atender às exigências da voz artística o ator precisa descobrir suas possibilidades vocais, desenvolver seu potencial e utilizá-lo de forma livre, é preciso trabalhar, simultaneamente, a técnica e a imaginação (BERRY, 2006).

Quinteiro (1989) ressalta que é muito difícil convencer o ator de que o conhecimento técnico é facilitador do seu trabalho com a emoção. Em geral, o ator rejeita a técnica em detrimento de alcançar resultados imediatos para sua prática interpretativa, mas, de forma contraditória, se aproxima da técnica como forma de garantir artefatos excepcionais que o socorram na hora de pisar o palco. O uso da voz em cena pelo ator é uma atividade que envolve muitos mitos, mas pouca objetivação científica.

Os aspectos físicos que constituem a voz humana são justamente os artefatos que tem o ator para manipular e criar as vozes em cena. Cada ator tem sua individualidade sonora, seus ajustes, seu potencial e sua capacidade. É preciso conhecer esse potencial para, a partir desse conhecimento, poder desenvolver e ampliar suas habilidades e capacidades vocais, o que resulta em poder atender às exigências do trabalho estético e criativo sem prejuízo para a saúde vocal. É nesse aspecto que arte e técnica se encontram e que a técnica fornece subsídios para o exercício da arte.

\section{Considerações sobre os parâmetros constitutivos da qualidade vocal}

A dinâmica vocal depende em grande parte do ciclo respiratório. Sabe-se que a respiração é o elemento propulsor da voz, tanto com relação ao aspecto físico como com relação ao aspecto da psicodinâmica emocional do indivíduo. A respiração facilmente se altera em resposta a estímulos tanto internos como externos, pois reflete a pulsão básica da vida. Além disso a respiração é um dos elementos-chave na busca das emoções e deve ser bem treinada para a pesquisa de vozes cênicas (QUINTEIRO, 1989). Por meio do sopro respiratório produzimos os sons que são articulados e amplificados nas cavidades superiores. A simples produção de uma vogal depende do equilíbrio entre as forças aerodinâmicas da corrente aérea pulmonar e as forças mioelásticas da laringe. A emissão prolongada de uma vogal, por exemplo, requer um controle aprimorado do sistema nervoso central e a falta desse controle pode indicar desde falta de treinamento vocal, até mesmo um indício de doença neurológica. $\mathrm{Na}$ fala encadeada a respiração fornece o suporte para que as frases possam ser pronunciadas com clareza, para que os sons dos finais de palavras, ou o próprio final da frase, possam ser escutados, além disso a respiração representa um verdadeiro fole ao possibilitar a projeção da voz no espaço de forma adequada.

Um outro parâmetro importante da qualidade vocal é a altura, que está diretamente ligado à frequiência de vibração das pregas vocais. Ainda que cada indivíduo apresente sua altura vocal característica, variações de altura - grave, agudo, médio - estão diretamente ligadas à intenção do discurso. A produção de sons mais graves exige o rebaixamento de laringe e encurtamento de pregas vocais, ao passo que a agudização da voz exige a elevação da laringe e o tensionamento maior das pregas vocais. É através das variações de altura que podemos perceber uma fala alegre ou melancólica e até mesmo intuir determinada personalidade - mais austera ou mais dependente, por exemplo.

A intensidade é também outro parâmetro importante da qualidade vocal e, em termos físicos, está diretamente relacionado à pressão subglótica exercida pela coluna de ar que advém dos pulmões. Do ponto de vista psicológico a variação na intensidade permite ao ouvinte fazer diferentes interpretações de como o emissor lida com os limites pessoais e o limite do outro. Por isso, o controle da intensidade requer do emissor uma consciência perfeita da dimensão (física e psicológica) do outro e de como sua voz será projetada no ambiente (BEHLAU e ZIEMER, 1988; BEHLAU, 2001). Na fala encadeada, as variações de intensidade constituem as ênfases dadas à enunciação e são elas as responsáveis por facilitar a compreensão do sentido do texto.

O reforço da intensidade é possibilitado pela dinâmica da voz nas caixas de ressonância. Através da ressonância algumas freqüências da fala são amplificadas enquanto outras são amortecidas. A ressonância é a principal responsável pelos aspectos estéticos da voz: é ela que torna a voz agradável e contribui para a projeção da voz no espaço. O uso desequilibrado das caixas de ressonância, seja a propósto ou não, exprime padrões emotivos do falante como, por exemplo, uma ressonân-

DAPesquisa, Florianópolis, v.3 n.5, p.1295-1301, 2008. 
cia proponderantemente oral empresta uma característica afetada ao emissor, o que revela uma personalidade narcisista (BEHLAU e ZIEMER, 1988). O uso equilibrado dos ressonadores corporais possibilita, além de projeção e qualidade vocal adequadas, menor desgaste, ou seja, a utilização maior do potencial vocal com menor esforço.

O parâmetro da articulação indica os ajustes motores dos órgãos fonoarticulatórios que o falante utiliza para a pronúncia de palavras e frases (BEHLAU e PONTES, 1995; BEHLAU, 2001). Segundo esses autores, uma articulação clara e bem definida indica controle da dinâmica fonoarticulatória e transmite franqueza, credibilidade, desejo de ser compreendido, ainda que a qualidade vocal do falante não seja especialmente bela ou potente. Mas, quando a fala encadeada carece de exatidão articulatória, o conteúdo da mensagem passa desapercebido e, consequentemente, não prende a atenção do ouvinte. Vale lembrar que o ritmo e a velocidade da fala são dois aspectos intimamente ligados à articulação.

Todos esses aspectos físicos compõem a dinâmica da qualidade vocal e estão presentes nos ajustes pessoais que cada sujeito faz no momento em que fala. Para o ator, dada sua exigência profissional da voz, conhecer esses parâmetros se traduz em uma importante ferramenta para norteá-lo no trabalho de desenvolvimento e aperfeiçoamento de seu potencial vocal. Com isso, durante o trabalho com a disciplina de expressão vocal do curso de artes cênicas da Universidade do Estado de Santa Catarina foi proposto o uso de um instrumento de avaliação dos parâmetros da psicodinâmica vocal que pudesse fornecer informações técnicas, precisas e objetivas, a respeito da capacidade, tipo e controle da respiração, qualidade e controle da emissão sonora e coordenação pneumofonoarticulatória na fala encadeada. Através desse instrumento buscou-se acompanhar o desenvolvimento dos aspectos individuais relacionados à técnica vocal, bem como objetivou-se nortear as atividades programadas pelo professor em sala de aula.

Nesse artigo serão apresentadas as principais medidas resultantes da aplicação desse instrumento de avaliação durante um período de três semestres da disciplina e discutida a implicação desses resultados para a saúde vocal dos sujeitos, bem como os encaminhamentos procedentes.

\section{O protocolo de avaliação}

O protocolo de avaliação dos parâmetros da psicodinâmica vocal é amplamente utilizado na clínica fonoaudiológica da voz pois avalia, através de medidas de tempo de fonação de cinco diferentes fonemas: duas consoantes e três vogais, a dinâmica vocal do sujeito (BEHLAU e PONTES, 1995). O protocolo consiste em medidas de tempo médio de fonação sustentada, com projeção média, para os fonemas: /s/, /z/, /a/, /i/ e /u/.

A emissão prolongada do fonema fricativo médio surdo /s/, por não exigir a vibração das pregas vocais, permite avaliar a capacidade e o controle do suporte aéreo pulmonar, ou seja, avaliar a fonte friccional do som. Vale lembrar que a variação de intensidade está diretamente ligada à capacidade e controle dessa fonte friccional. A emissão do fonema fricativo médio sonoro /z/ coloca em atividade a fonte glótica, ou seja, a vibração das pregas vocais e informa sobre a eficiência glótica (BOONE, 1996). É essa eficiência que permitirá uma fonação, por exemplo, sustentada, sem quebras e de qualidade.

As medidas de tempo de fonação para os fonemas /s/ e /z/ são importantes medidas diagnósticas da clínica de voz $^{2}$. Medidas abaixo de 15 segundos, em ambos os fonemas, indicam um comprometimento do suporte respiratório. Além disso, um tempo de fonação de /z/, maior em 3 segundos com relação ao tempo de fonação de /s/, indica uma hipercontração de pregas vocais, ou seja, uma produção fonatória com prejuízo para a saúde vocal (BOONE \& Mc FARLANE, 1994).

A emissão prolongada das vogais/a/, /i/ e /u/ informa sobre a habilidade do sujeito em controlar as forças aerodinâmicas e mioelásticas quando da variação do trato articulatório. A vogal /a/ é a vogal oral mais aberta, baixa e central. A vogal /i/ é mais anterior, alta e não arredondada, ao passo que a vogal / u/ é mais posterior, alta e arredondada (Silva, 1999). Em função dessas características fonéticas a emissão da vogal /a/, por exemplo, permite avaliar as mínimas alterações no equilíbrio mioelástico da laringe enquanto a emissão das vogais /i/ e / u/ permite avaliar o fechamento velar e o uso das caixas de ressonância (BEHLAU e PONTES, 1995; BEHLAU, 2001). 
As medidas de tempo de fonação de cada um desses cinco fonemas resultam em uma medida de tempo máximo de fonação (TMF). Essa medida revela-se particularmente importante porque fornece informações sobre o mecanismo de recarga aérea. Sabe-se que na fala encadeada o sujeito necessita fazer recargas a cada um terço de seu tempo máximo de fonação (BEHLAU e PONTES, 1995). Assim, as inspirações nas situações de fala deverão ocorrer, com maior ou menor freqüência, proporcionalmente à medida do TMF. A necessidade de recarga constante, por exemplo, impede o sujeito de se expressar por frases mais longas ou, dificulta a utilização dos recursos vocais próprios na interpretação, tais como as variações de intensidade e/ou altura que recrutam suporte aéreo adequado.

As medidas de TMF, segundo pesquisas brasileiras (BEHLAU e PONTES, 1995), estão na faixa de 20 segundos para os homens e 14 segundos para as mulheres. Valores abaixo de 10 segundos são altamente significantivos de anormalidades. Não foi encontrado da- dos de pesquisas que indiquem parâmetros de normalidade para vozes de profissionais do teatro.

Outra medida resultante do protocolo de avaliação é a relação estabelecida entre os tempos de fonação do fonema /z/ e /s/. Essa relação indica a capacidade do sujeito de sustentar a dinâmica fonatória de modo eficiente, a partir de uma suplência de ar. Tal medida é obtida dividindo-se o tempo médio de fonação de /z/ pelo tempo médio de fonação de / s / que deve corresponder ao valor 1.0, o que indica que o tempo de emissão do fonema surdo se equipara à emissão do fonema sonoro. Segundo a literatura valores até a proporção de 1.2 são considerados normais; de hipercinesia ${ }^{3}$; valores iguais ou superiores a 1.2 indicam falta de coaptação correta das pregas vocais à fonação, descontrole laríngeo à passagem do ar ou indícios de patologia vocal (BEHLAU e PONTES, 1995).

A seguir serão especificados a aplicação do protocolo e apresentada a análise e discussão dos resultados.

\section{Metodologia}

Participaram dessa pesquisa 23 alunos matriculados na disciplina de expressão vocal do curso de artes cênicas da Universidade do Estado de Santa Catarina. Os sujeitos foram avaliados através do protocolo de avaliação da qualidade vocal durante três semestres letivos consecutivos.

Para a coleta dos dados do protocolo cada sujeito deveria fazer três emissões li- vres e prolongadas, após uma inspiração profunda, de cada um dos fonemas (/s/, / z/, /a/, /i/, $/ \mathrm{u} /$ ) e contar, em segundos, o seu respectivo tempo de fonação. A emissão foi realizada em pé, ou sentado, e deveria apresentar tonalidade e intensidade naturais e habituais do sujeito. Os tempos das três emissões resultaram em uma média de fona- ção para cada fonema em questão. A média dos tempos de fonação para cada fonema re- sultou em uma média que se constituiu em uma medida de tempo máximo de fonação (TMF).

As medidas de TMF foram comparadas entre dois momentos distintos durante $\mathrm{O}$ transcorrer da pesquisa ${ }^{4}$ :

$\mathrm{T}_{1}$ - a primeira tomada de tempo realizada para cada sujeito e

$\mathrm{T}_{2}$ - a última tomada de tempo realizada para cada sujeito.

Outra medida de análise para esse estudo foi a proporção entre os tempos médios de fonação dos fonemas /s/-/z/. Essa proporção foi obtida dividindo-se a média do tempo de fonação do fonema /z/ pela média do tempo de fonação do fonema /s/. Da mesma forma que para as medidas de TMF, foram calculadas as proporções entre /z/-/

$\mathrm{s} /$ para os momentos $\mathrm{T}_{1}$ e $\mathrm{T}_{2}$ durante o transcorrer dessa pesquisa.

\section{Resultados}

Os tempos médios de fonação para a emissão de cada um dos fonemas: /s/, /z/, / a/, /i/, /u/, de cada sujeito, foram transformados em médias de tempo máximo de fonação (TMF) em cada um dos dois momentos estudados $\mathrm{T}_{1}$ e $\mathrm{T}_{2}$. Além disso, foram também calculadas as proporções entre a emissão dos

\footnotetext{
${ }^{3}$ Hipercinesia refere-se ao aumento da motilidade de pregas vocais, o que intensifica o atrito na região e predispõe o sujeito ao aparecimento de nódulos de pregas vocais (SOUZA e HANAYAMA, 2005)

${ }^{4}$ Por se tratar de pesquisa que trabalhou com dados longitudinais coletados a partir da assistência dos sujeitos à disciplina em questão, muitas vezes, a coleta dos dados ficou prejudicada pela ausência dos sujeitos nos diferentes momentos ao longo do período estudado. Dessa forma, para que fosse possível uma análise mais precisa e abrangente, considerou-se, para esse estudo, apenas duas sessões de coleta de dados para cada sujeito.
}

DAPesquisa, Florianópolis, v.3 n.5, p.1295-1301, 2008. 
fonemas /z/-/s/ nestes mesmos momentos do estudo. A Tabela 1 apresenta as medidas de tempo máximo de fonação (TMF) e a relação /s/-/z/ para cada sujeito nos dois momentos estudados $\mathrm{T}_{1}$ e $\mathrm{T}_{2}$.

Tabela 1 - Tempo máximo de fonação e relação /s/-/z/ para os momentos $\mathrm{T}_{1}$ e $\mathrm{T}_{2}$

\begin{tabular}{cccccc}
\hline \multirow{2}{*}{ Sujeitos } & \multirow{2}{*}{ Sexo } & \multicolumn{2}{c}{ TMF } & \multicolumn{2}{c}{ Relaçăo } \\
\cline { 3 - 6 } & & $\mathbf{T}_{1}$ & $\mathrm{~T}_{2}$ & $\mathrm{~T}_{1}$ & $\mathrm{~T}_{2}$ \\
\hline S1 & $\mathrm{F}$ & 23,8 & 26,0 & 0,7 & 0,8 \\
S2 & $\mathrm{F}$ & 10,2 & 15,8 & 1,0 & 0,8 \\
S3 & $\mathrm{F}$ & 13,8 & 17,8 & 1,0 & 0,7 \\
S4 & $\mathrm{F}$ & 14,0 & 17,4 & 0,8 & 0,9 \\
S5 & M & 23,4 & 24,0 & 1,1 & 0,9 \\
S6 & M & 20,6 & 23,8 & 1,0 & 1,0 \\
S7 & F & 15,2 & 22,4 & 0,7 & 0,7 \\
S8 & M & 24,0 & 24,8 & 1,2 & 1,1 \\
S9 & F & 22,0 & 30,6 & 0,9 & 0,7 \\
S10 & F & 12,6 & 14,8 & 1,5 & 0,9 \\
S11 & F & 12,6 & 18,2 & 0,7 & 1,0 \\
S12 & M & 11,4 & 15,2 & 1,2 & 1,1 \\
S13 & F & 14,8 & 12,6 & 1,2 & 1,1 \\
S14 & F & 12,6 & 23,2 & 1,0 & 0,9 \\
S15 & F & 8,2 & 11,2 & 1,1 & 0,9 \\
S16 & M & 26 & 28,6 & 1,2 & 0,9 \\
S17 & F & 10,8 & 14,6 & 1,9 & 0,9 \\
S18 & F & 16,8 & 23,2 & 0,9 & 1,0 \\
S19 & M & 23,6 & 25,4 & 1,2 & 1,2 \\
S20 & M & 20 & 23,4 & 1,1 & 1,1 \\
S21 & M & 11,6 & 11,0 & 1,2 & 1,1 \\
S22 & F & 14,4 & 17,8 & 0,9 & 0,9 \\
S23 & F & 11 & 15,4 & 0,7 & 1,6 \\
\hline & & & & &
\end{tabular}

Com relação às medidas de $\mathrm{TMF}$ os resultados mostraram que houve um crescimento dessas medidas entre as etapas $T_{1}$ e $\mathrm{T}_{2}$ em vinte e um, dos vinte e três sujeitos estudados. No momento $\mathrm{T}_{2}$ dois sujeitos (S13, S21) apresentaram medidas de TMF menores do que as medidas no momento $\mathrm{T}_{1}$. Com relação ao momento $\mathrm{T}_{1}$ observouse ainda que um sujeito apresentava valores com alta significância de anormalidade vocal, o sujeito S15.

Com relação às médias de TMF esperadas para homens e mulheres observou-se no momento $\mathrm{T}_{1}$ sete sujeitos femininos (S2, S10,
S11, S14, S15, S17, S23) e dois sujeitos masculinos com valores abaixo do esperado (S12, S21). Já no tempo $\mathrm{T}_{2}$, após um período de exercitação de aspectos da qualidade física da $\operatorname{voz}(((4))))$, observou-se dois sujeitos femininos (S13, S15) e dois sujeitos masculinos (S12, S21) com valores abaixo do esperado. Note-se, no entanto, que dentre os sujeitos femininos com valores abaixo do esperado em $\mathrm{T}_{2}$, apenas o sujeito $\mathrm{S} 15$ também apresentava valores inadequados em $\mathrm{T}_{1}$. Com isso é possível inferir que, nesse período, houve um crescimento geral do grupo quanto à adequação do TMF.

Com relação à análise da relação /s//z/ os resultados mostraram que no tempo $\mathrm{T}_{1}$ doze sujeitos apresentaram inadequações com relação a essa proporção, seja abaixo ou acima dos valores de referência (S1, S7, S8, S10, S11, S12, S13, S16, S17, S19, S21, S23). Já no tempo $\mathrm{T}_{2}$ cinco sujeitos apresentaram proporções entre /s/-/z/ inadequadas (S3, S7, S9, S19, S23). Desses cinco sujeitos, apenas três sujeitos faziam parte do grupo inadequado em $\mathrm{T}_{1}$ (S7, S19, S23). Dessa forma, observou-se também com relação a esse aspecto avaliado, crescimento substancial do grupo com relação aos ajustes do mecanismo glótico à fonação.

\section{Discussão}

A análise das medidas de TMF entre os dois momentos pesquisados, $\mathrm{T}_{1}$ e $\mathrm{T}_{2}$, mostrou que grande parte dos sujeitos (91,3\%) aumentou seus desempenhos no decorrer desse período. Esse resultado foi corroborado também pela diminuição no número de sujeitos que, entre os momentos $\mathrm{T}_{1}$ e $\mathrm{T}_{2}$, estavam com a média de TMF abaixo dos valores expres- sos pela média da população estudada em pesquisas brasileiras (Behlau e Pontes, 1995). Observou-se que no momento $\mathrm{T}_{1}$ havia nove sujeitos, entre homens e mulheres, com valores de TMF inferiores à média da população, enquanto no momento $\mathrm{T}_{2}$, apenas três desses sujeitos ainda apresentavam valores abaixo do esperado (S12, S15, S21).

Com relação aos sujeitos S12 e S15 que no momento $\mathrm{T}_{2}$ ainda apresentavam valores de TMF abaixo do esperado para a média da população, duas situações podem ser descritas. No caso do sujeito S12, masculino, no momento $\mathrm{T}_{2}$, observa-se aumento do TMF e da qualidade de sua fonação, o que é expresso pela relação /s/-/z/ com valor de 1.1. Esses

${ }^{5}$ Tais aspectos dizem respeito ao trabalho com respiração (tipo, capacidade e controle), articulação, ressonância, altura, intensidade e tessitura vocal.

DAPesquisa, Florianópolis, v.3 n.5, p.1295-1301, 2008. 
dados parecem indicar que, para esse sujeito, os exercícios e atividades desenvolvidos durante esse período, apesar de terem favorecido uma adequada propriocepção para que realizasse mais satisfatoriamente uma fonação de qualidade, ainda foi insuficiente para suprir suas necessidades de condicionamento e controle do suporte aéreo pulmonar. Necessariamente o sujeito S12 precisa de um tempo maior de prática dos exercícios para aumento dessa capacidade e controle do sopro expiratório para sustentar a atividade da fala encadeada. Já com relação ao sujeito S15, feminino, percebe-se que também houve progressos quanto ao condicionamento do suporte aéreo pulmonar, mas, ainda assim, esse condicionamento sofre prejuízos quanto ao controle efetivo para uma fonação de qualidade, o que muito provavelmente se justifica em função de uma patologia vocal já instalada. O sujeito S15 foi orientado a procurar atendimento fonoaudiológico desde o início desse estudo.

Apesar desses resultados positivos, dois sujeitos no momento $T_{2}$ apresentaram diminuição dos TMF (S13, S21) em relação ao momento $\mathrm{T}_{1}$. Esse resultado pode ser ponderado observando-se os dados relativos à proporção entre os fonemas /s/-/z/ que denota a qualidade da dinâmica fonatória. No momento $\mathrm{T}_{1}$ esses sujeitos apresentavam valores de 1.2 para essa proporção, o que aponta para a falta de coaptação correta das pregas vocais. Em contrapartida, no momento $\mathrm{T}_{2}$, esses sujeitos apresentaram valores de 1.1 para essa proporção, o que demonstrou melhora quanto ao controle laríngeo e à qualidade da fonação. Muito provavelmente, em $\mathrm{T}_{1}$, esses sujeitos produziram tempos melhores de fonação com sobrecarga do mecanismo de fechamento glótico e, após a prática de sala de aula, desenvolveram melhores ajustes vocais.

A análise da relação /s/-/z/ entre os dois momentos pesquisados também mostrou progresso no desempenho geral dos sujeitos ao longo desse período: no momento $T_{2}$ apenas três, dos doze sujeitos ao início do estudo, apresentaram inadequações. $\mathrm{O}$ que se observou a partir da análise dos resultados apresentados por esses três sujeitos (S7, S19, S23) é que os sujeitos S7 e S19 se beneficiaram dos exercícios propostos ao longo do período para aumentar seus TMF, mas não conseguiram desenvolver a sustentação equilibrada da dinâmica fonatória, exibindo aspectos de hipercinesia e hipercontração de pregas vocais que são prejudiciais à saúde vocal. Esses sujeitos, para desenvolverem sua voz profissional, sem prejuízo para sua saúde vocal, precisam equilibrar esses aspectos o que pode significar a necessidade de suporte terapêutico. Quanto ao sujeito S23, tanto no momento $\mathrm{T}_{1}$ como no momento $\mathrm{T}_{2}$ observouse inadequação das proporções de /s/-/z/, ainda que tenha aumentado seu TMF nesse perìodo. Foi possível notar através da aná- lise dos dados que esse aumento no TMF se faz com grande oscilação dos índices de /s / -

/z/, o que denota grande desequilíbrio do controle glótico, que pode ser a manifestação inicial de patologia vocal. Dessa forma, foi sugerido ao sujeito S23 que buscasse atendimento fonoaudiológico para que pudesse desenvolver trabalho específico voltado tanto às suas necessidades do dia-a-dia bem como de sua futura profissão.

Os resultados mostraram ainda que no momento $\mathrm{T}_{2}$ dois sujeitos (S3, S9), que apresentavam proporções entre /s/-/z/ e TMF adequados em $\mathrm{T}_{1}$, passam a exibir índices inadequados da proporção /s/-/z/. Esses sujeitos possivelmente se encontram em um período de transição em que aumentaram o suporte aerodinamico, mas não conseguiram ainda equilibrar as forças mioelásticas para a fonação. Esses sujeitos apresentaram durante o estudo perfis diferentes dos apresentados pelos sujeitos analisados anteriormente, uma vez que não apresentavam inadequações no momento $\mathrm{T}_{1}$ quanto ao mecanismo de fechamento glótico. Assim, não se justifica, no momento, a indicação de trabalho terapêutico especializado.

Esses resultados parecem demonstrar que o trabalho técnico desenvolvido durante os intervalos pesquisados foi capaz de melhorar tanto os padrões de TMF dos sujeitos que estavam abaixo dos padrões representativos da população brasileira, como foi capaz de aumentar, de forma geral, os TMF dos sujeitos estudados conferindo-lhes maior capacidade e controle respiratório. Esse aumento permite disponibilizar o aparato fonador para as exigências da fala encadeada e da fala cênica, o que deve se refletir em necessidades menores de recargas aéreas para realizar a fala encadeada (o sujeito poderá pronunciar frases mais longas com períodos menores de inspiração) e, conseqüentemente, possibilitar o uso com maior liberdade dos recursos vocais para a interpretação.

Além disso, através da análise da relação /s/-/z/ pôde-se verificar que durante o período estudado grande parte dos sujeitos aperfeiçoou os ajustes sutis do mecanismo glótico o que tornou possível uma fonação mais equilibrada e de maior qualidade. Essa harmonização entre o sopro respiratório e uma emissão de qualidade permite utilizar

DAPesquisa, Florianópolis, v.3 n.5, p.1295-1301, 2008. 
as qualidades físicas da voz (altura, intensidade, ressonância e articulação) de maneira mais adequada no momento de expressar o pensamento e os sentimentos de um personagem e alcançar esteticamente os sentidos do ouvinte. Com isso foi possível desenvolver o potencial dos recursos vocais próprios e disponibilizá-los de forma livre e sem prejuízo à saúde vocal dos sujeitos.

\section{Considerações finais}

O trabalho e as exigências de alta qualidade e demanda da voz do ator o colocam em um grupo privilegiado de risco para o desenvolvimento de patologias vocais. Foi argumentado que esse profissional precisa desenvolver habilidades vocais suficientes para responder às exigências de seu trabalho sem comprometimento de sua saúde. Para tanto, $\mathrm{o}$ ator precisa conhecer aspectos físicos de seu aparelho fonador que compõem a dinâmica vocal e que se constituem em instrumento de trabalho e aperfeiçoamento de seu potencial de voz. Nesse sentido, a presente pesquisa propôs o uso de um protocolo de avaliação da dinâmica da voz que forneceu dados objetivos e palpáveis ao aluno do curso de artes cênicas para que conhecesse as características particulares de seu mecanismo de fonação e, ao mesmo tempo, o ajudasse a desenvolver sua potencialidade vocal sem risco para sua saúde vocal. Da mesma forma esse protocolo forneceu ao professor suporte técnico para o direcionamento do trabalho pedagógico em sala de aula, o que possibilitou atender às necessidades particulares do grupo. $\mathrm{O}$ protocolo mostrou-se útil, também, para balizar o encaminhamento de possíveis casos de patologia vocal. Com isso, sugere-se que o trabalho com a expressão vocal dos profissionais da voz seja acompanhado da análise constante de marcos objetivos da saúde vocal para que assim se possa preservá-la.

\section{Referências Bibliográficas}

BEHLAU, M. (Org.) O livro do especialista. São Paulo: Revinter, 2001.

BEHLAU, M. e PONTES, P. Avaliação e Tratamento das Disfonias. São Paulo: Lovise, 1995.

BEHLAU, M. e ZIEMER, R. Psicodinâmica Vocal. In: FERREIRA, L. P. (Org.) Trabalhando a voz: vários enfoques em fonoaudiologia. 2a edição. São Paulo: Summus, 1988.

BERRY, C. La voz y el actor. Barcelona: Alba editorial, 2006.

BOONE, D. R. \& McFARLANE, S. C. A voz $e$ a terapia vocal. $5^{\mathrm{a}}$ edição. Porto Alegre: Artes
Médicas, 1994.

BOONE, D. Sua voz está traindo você?: como encontrar sua voz natural. Porto Alegre: Artes Médicas, 1996.

FERRACINI , R. A arte de não interpretar como poesia corpórea do ator. Campinas, SP: Editora da UNICAMP, 2001.

QUINTEIRO, E. A. Estética da voz: uma voz para o ator. São Paulo: Summus, 1989.

SILVA, T. C. Fonética e Fonologia do Português: roteiro de estudos e guia de exercícios. São Paulo: Contexto, 1999.

SOUZA, O. C. de e HANAYAMA, E. M. Fatores psicológicos associados a disfonia funcional e a nódulos vocais em adultos. Revista CEFAC, v.7, n.3., p. 388-397, 2005.

STANISLAVSKI, C. A construção da personagem. $4^{\text {a }}$ edição. Rio de Janeiro: Civilização Brasileira, 1986.

VILKMAN, E. Voice problems at work: a challenge for occupational safety and health arrangement. Folia Phoniatrica et Logopaedica, v.52, n. 1-3, p. 120-125, 2000.

DAPesquisa, Florianópolis, v.3 n.5, p.1295-1301, 2008. 